\title{
ASSESSMENT OF EFFECTIVENESS OF RESIDUAL STRESS LOWERING IN CIRCUMFERENTIAL JOINTS OF PIPES AFTER POSTWELD EXPLOSION TREATMENT
}

\author{
A.G. BRYZGALIN \\ E.O. Paton Electric Welding Institute, NASU \\ 11 Bozhenko Str., 03680, Kiev, Ukraine. E-mail: office@paton.kiev.ua
}

\begin{abstract}
It is established that at application of earlier developed procedure of calculation of explosion treatment modes for pipe circumferential joints the extent of residual stress lowering depends on their initial level. In particular, at explosion treatment of pipes without the circumferential weld the induced compressive stresses are essentially lower than welding stresses, whereas the latter are practically completely relieved at treatment of welds of similar pipes by the same modes. Scatter of induced compressive stresses in pipes of different typesizes did not exceed the measurement error. Dependence of explosion treatment effectiveness on the magnitude of initial welding stresses was determined, which is of a nonlinear nature. Presence of such a dependence allows prediction of treatment results and correction of modes depending on requirements made of treatment results. Fundamental difference of the mechanisms of residual stress lowering at heat treatment and explosion treatment is shown. 9 Ref., 2 Tables, 4 Figures.
\end{abstract}

Key words: effectiveness, explosion treatment, heat treatment, residual stresses, deformations, circumferential weld, pipelines

Reaching a zero stress level in the weld, being, as a rule, the weakest point of the structure, can be regarded as the optimum result of lowering residual stresses (RS) by postweld treatment. As shown in [1], application of calculation method to determine the modes of explosion treatment (ET) allows sufficiently effective lowering of RS in pipes of various typesizes. It is of interest to find out how close the calculated modes are to optimum ones, and to assess the possibilities of their correction when solving various practical problems. With this purpose additional verification of the calculation method was conducted on one-piece seamless pipes with the following typesize: $115 \times 4$ (steel 20$), 115 \times 10$ (steel $17 \mathrm{G} 1 \mathrm{~S}), 160 \times 6($ steel $17 \mathrm{G} 1 \mathrm{~S}), 216 \times 7 \mathrm{~mm}$

Table 1. Residual stresses at ET of seamless pipes

\begin{tabular}{||c|c|c|c||}
\hline \hline $\begin{array}{c}\text { Pipe typesize } \\
(2 R \times h), \mathrm{mm}\end{array}$ & $\sigma_{\mathrm{y}}, \mathrm{MPa}$ & $\sigma_{\mathrm{f}}, \mathrm{MPa}$ & $\Delta \sigma, \mathrm{MPa}$ \\
\hline $115 \times 4$ & 240 & -50 & 50 \\
\hline $115 \times 10$ & 350 & -70 & 70 \\
\hline $160 \times 6$ & 350 & -70 & 70 \\
\hline $216 \times 7$ & 240 & -60 & 60 \\
\hline
\end{tabular}

(steel 20). This allowed eliminating experimental error introduced by making the weld.

Explosive charges were mounted on pipe samples symmetrically relative to a certain diametral section plane, simulating the geometry of ET of pipes with finished circumferential welds. Calculation of experimental modes was conducted as it was done before for pipes with a weld, the center of which was conditionally located in the above section plane. Circumferential stresses after ET were measured in the same plane on the pipe outer surface.

Measurement results are given in Table 1. Initial RS values are equal to zero $\left(\sigma_{\text {in }}=0\right)$, and final stresses after ET are equal to $\sigma_{f}$ values in the respective column of Table 1. ET effectiveness $\Delta \sigma=\sigma_{\text {in }}-\sigma_{\mathrm{f}}=-\sigma_{\mathrm{f}}$.

Scatter of $\Delta \sigma$ value is on the level of RS measurement error. Table 2 gives the results of RS measurement in circumferential pipe welds, published in [1].

Effectiveness of ET of circumferential pipe welds depends on a multitude of factors, the most significant of which are as follows: pipe geometrical parameters (radius $R$, wall thickness $h$ ), pipe material strength $\sigma_{\mathrm{y}}$, initial $\mathrm{RS} \sigma_{\text {in }}$, pipe internal pressure $P$, pipe material temperature at the moment of treatment $T$.

It should be noted that stress measurement results which are presented in Tables 1 and 2, were derived when performing ET on pipes without internal pressure and at small variation of 
ambient temperature $\left(25 \pm 10{ }^{\circ} \mathrm{C}\right)$, therefore, these factors did not influence ET effectiveness.

Of all the significant parameters, $\sigma_{\text {in }}$ parameter, which was not taken into account in development of mode determination procedure, remained unconsidered. An essentially smaller $\Delta \sigma$ value in seamless pipes, compared to $\Delta \sigma$ in pipes with circumferential welds, is indicative of the presence of a dependence between initial RS and their lowering value in the case of selection of ET modes in keeping with the developed procedure. Let us analyze the derived experimental results.

Value of initial RS for different pipes (see Table 2) varies from 150 up to $300 \mathrm{MPa}$. After ET final RS values fell within the range of $\pm 50 \mathrm{MPa}$, i.e. despite the different level of initial $\mathrm{RS}$, a quite stable result for $\sigma_{\mathrm{f}}$ was achieved, even though for different pipes of both groups (with and without circumferential welds) thickness differed by 4.3 times, diameter -6 times, and diameter-to-thickness ratio -6.6 times.

To assess the influence of initial RS on treatment effectiveness, let us present the data of all the experiments on ET graphically in the form of a family of points in the co-ordinate plane $\left(\sigma_{\text {in }}\right.$, $\Delta \sigma)$ (Figure 1).

Linear correlation coefficient between $\sigma_{\text {in }}$ and $\Delta \sigma$ values is equal to 0.97 that is indicative of availability of a functional link between these parameters, close to a linear one. Let us present this dependence in the form of a straight line, flowing through point (0.63), which corresponds to mean value of stress variation at ET of seamless pipes. Selection of this point as the basic one for drawing a straight line relies on the fact that for seamless pipes errors of measurement of RS from welding are eliminated that determines its essential significance. Equation of a straight line defining the dependence between $\sigma_{\text {in }}$ and $\Delta \sigma$ for this experimental series, becomes

$$
\Delta \sigma=0.72 \sigma_{\text {in }}+63[\mathrm{MPa}]
$$

Presence of such a dependence enables predicting RS level after ET, and mode correction if required, and subsequent precising of the procedure of explosion impact parameter calculation in order to control RS value in welds. On the whole, it can be assumed that ET is an effective method to control RS in circumferential pipe welds.

Other methods to lower welding stresses are well-known [2-4]. All of them are based on running of plastic deformations, compensating shrinkage welding stresses. RS create in the
Table 2. Circumferential residual stresses in pipe welds, MPa

\begin{tabular}{||c|c|c|c||}
\hline $\begin{array}{c}\text { Pipe typesizes } \\
(2 R \times h), \mathrm{mm}\end{array}$ & $\sigma_{\text {in }}, \mathrm{MPa}$ & $\sigma_{\mathrm{f}}, \mathrm{MPa}$ & $\Delta \sigma, \mathrm{MPa}$ \\
\hline $115 \times 4$ & 150 & -30 & 180 \\
\hline $160 \times 5$ & 200 & -50 & 250 \\
\hline $115 \times 8$ & 200 & -20 & 220 \\
\hline $150 \times 8$ & 250 & 0 & 250 \\
\hline $530 \times 7$ & 300 & 50 & 250 \\
\hline $530 \times 9$ & 300 & 50 & 250 \\
\hline $168 \times 14$ & 250 & 0 & 250 \\
\hline \multicolumn{4}{|l|}{ Note. All the given stress values are for pipe outer surface. } \\
\hline
\end{tabular}

welded joint a margin of internal elastic energy, owing to which such a joint is in the condition of unstable energy equilibrium. Realization of the process of elastic deformation transition into plastic deformations requires an energy «impulse» from an external source. Such a source can be heating (heat treatment), explosion (ET), vibrational, electric-pulse treatment, etc. However, in order to remove RS in circumferential pipe welds, local heat treatment is applied as the most effective of the above-mentioned ones. Tempering temperature for carbon and low-alloyed steels is usually assigned to be $680-720{ }^{\circ} \mathrm{C}$ with 60-120 min soaking time, depending on pipe wall thickness. This mode is applied both in local industry [5], and abroad (British standard B 33511961, Standard USA I B 37.1.0).

However, heat treatment involves high labour and energy consumption. It is known that duration of heat treatment of circumferential pipe welds in the field is 3-4 times longer than the welding time [6]. Moreover, heat treatment effectiveness is essentially lowered with greater pipe wall thickness, as this is accompanied by an increase of temperature gradient through wall thickness. And, finally, in connection with ap-

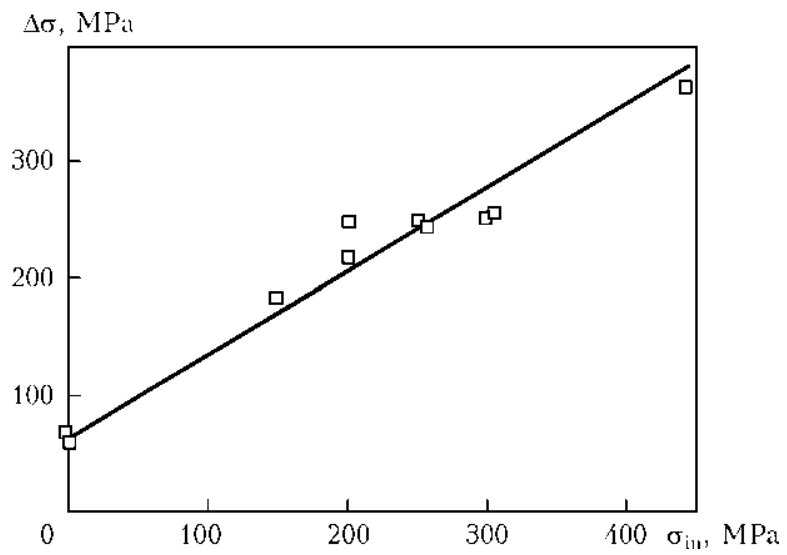

Figure 1. Dependence of the magnitude of residual stresses lowering on their initial value 

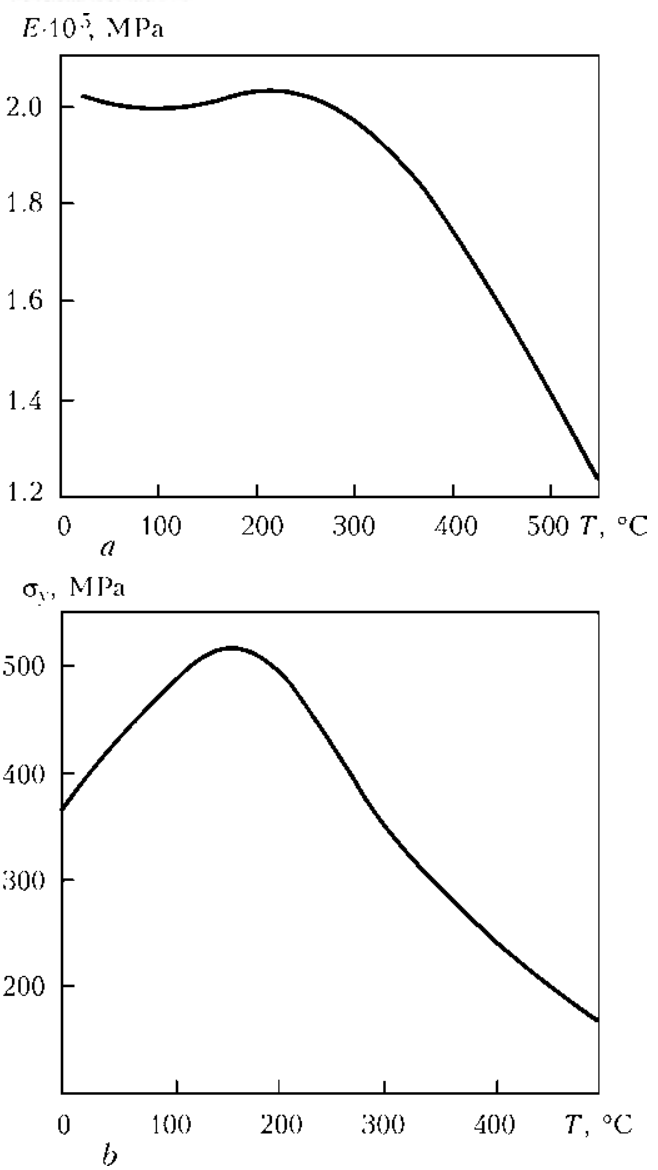

Figure 2. Dependence of modulus of elasticity $(a)$ and yield point $(b)$ of carbon steel on temperature

plication of pipes from higher strength steels (for instance, controlled-rolled steels), the risk of their softening as a result of overheating becomes higher.

It is known that ET is not inferior to heat treatment as to its effectiveness [7]. On the other hand, it is obvious that both the processes have completely different mechanisms of impact on welded joint, consideration of the principles of which (without allowing for diverse factors, af-

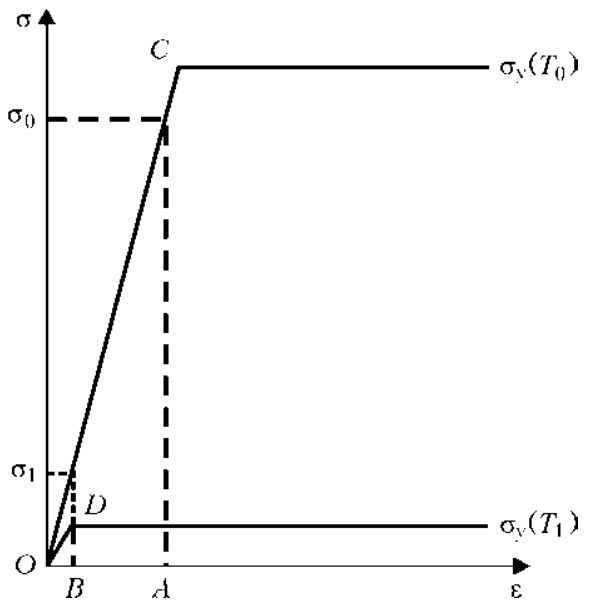

Figure 3. Ideal elastoplastic $\sigma^{-\varepsilon}$ diagram for steel at different temperatures fecting their effectiveness, but not changing the essence of the processes) appears to be rational.

Heat treatment. At uniform heating, thermal deformations are uniform over the entire metal volume, and in themselves they cannot lead to RS lowering. Heat treatment effect is achieved owing to the property of steel to change its yield point and modulus of elasticity with temperature change. Figure 2, $a$ gives dependencies of modulus of elasticity, and Figure 2, $b$ - those of yield point of carbon steel on temperature [8].

At heating of welded joint from $T_{0}$ up to $T_{1}$ (Figure 3) $E$ and $\sigma_{\mathrm{y}}$ decrease. Elastic deformations $\varepsilon_{1}$ corresponding to steel $\sigma_{\mathrm{y}}$ at temperature $T_{1}$ are shown in Figure 3 by section $O B$. The rest of deformation, which was elastic at $T_{0}$, will go into plastic deformation ( $B A$ section).

After welded joint cooling to $T_{0}$, modulus of elasticity will increase up to initial value, while elastic deformations will remain the same as at $T_{1}$. Then the stresses after heat treatment will be equal to

$$
\sigma_{1}=\varepsilon_{1} E_{0} .
$$

As we can see, after overall heat treatment RS are independent on the magnitude of their initial value. It should be noted that during soaking at heat treatment temperature further lowering of RS takes place through their relaxation by the diffusion mechanism. At local heat treatment the principle of RS lowering will remain the same.

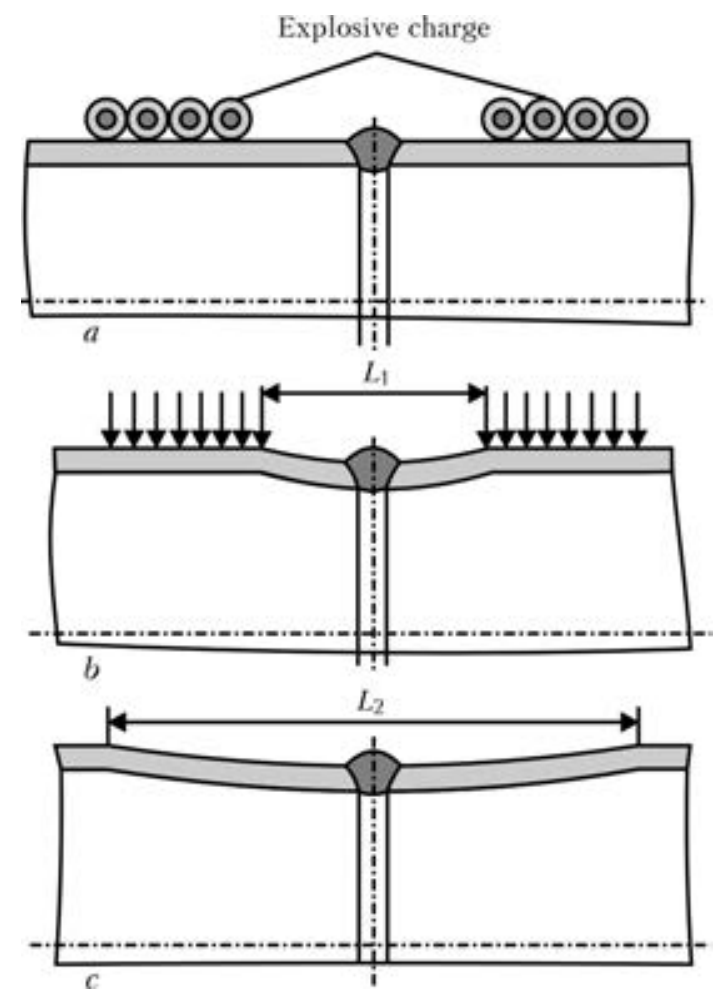

Figure 4. Schematic of ET process: $a$ - charge arrangement; $b$ - load application; $c$ - pipe wall deformation after ET 
However, additional RS of negligible magnitude will develop as a result of non-uniform thermodeformational cycle.

Explosion treatment. As a result of a complex thermodeformational process in welding, the circumferential weld and a certain zone of base metal adjacent to it have smaller radius than the rest of the pipe body [9]. The mechanism of RS lowering at ET of circumferential pipe welds by external charges consists in inducing plastic deformations, reducing the pipe radius in the section directly adjacent to the zone of plastic deformations of shrinkage due to welding. In this case RS are redistributed over a wider pipe section that leads to an essential lowering or complete elimination of peak tensile stresses in the weld (Figure 4).

At sufficiently extensive explosive loading such deformations can be induced in the pipe wall, that its radius under the charge is smaller than that of the circumferential weld. In this case the weld develops compressive stresses. Unlike heat treatment, ET performance does not affect weld metal structure (either positively or negatively). Numerous studies and experience of ET application show that the induced dynamic loads do not lead to development of defects present in the welded joint and base metal in the form of lacks-of-penetration, pores, undercuts, foreign inclusions, etc.
Conducted analysis shows that expansion of ET technological capabilities can be achieved by prediction and regulation of its results.

1. Bryzgalin, A.G. (2013) Calculation of parameters of explosion treatment for reduction of residual stresses in circumferential welds of pipelines. The Paton Welding J., 8, 31-36.

2. Zubchenko, A.S., Koloskov, M.M., Amelianchik, A.V. et al. (2002) Investigation of effect of deformation treatment on residual stresses in circumferential welds. Ibid., 1, 2-9.

3. Kasatkin, B.S., Prokhorenko, V.M., Chertov, I.M. (1987) Stresses and strains in welding. Kiev: Vyshcha Shkola.

4. Lobanov, L.M., Pavlovsky, V.I., Lysak, V.V. (1989) Application of preliminary elastic deformation for control of stress-strain state in welding of thin-sheet structures from aluminium alloys. In: Welding of non-ferrous metals. Kiev: Naukova Dumka, 52-56.

5. SNiP III-42-80: Rules for performance and acceptance of works. Main gas pipelines. Moscow: Strojizdat.

6. Perunov, B.V., Kushnarenko, V.M. (1983) Corrosion prevention as a guarantee of efficiency. Chelyabinsk: YuUKI.

7. Dobrushin, L.D., Effendiev, E.E., Bryzgalin, A.G. (1985) Investigation of comparative efficiency of residual stress relaxation in circumferential welds of pipes from controlled rolling steel using explosion treatment. In: Application of explosion energy in welding technique. Kiev: PWI, 90-94.

8. Rabotnov, Yu.N. (1963) Strength of materials. Moscow: Fizmatgiz.

9. Makhnenko, V.I. (1976) Stress state in zones of circumferential butt joints of pipes during explosion treatment. In: Calculation methods for examination of kinetics of welding stresses and strains. Kiev: Naukova Dumka, 291-296. 